Mass Layoffs and Unemployment

By Andrew Caplin, Columbia University

John Leahy, Harvard University

December 1993

Discussion Paper No. 679

$$
d p-13994-679
$$


December 1993

\title{
MASS LAYOFFS AND UNEMPLOYMENT
}

\author{
ANDREW CAPLIN AND JOHN LEAHY \\ Columbia University and HaRvard UnIVERsity
}

Mass layoffs give rise to groups of unemployed workers who possess similar characteristics and therefore may learn from one another's experience searching for a new job. Two factors lead them to be too selective in the job offers that they accept. The first is an information externality: searchers fail to take into account the value of their experience to others. The second is an incentive to free ride: each worker would like others to experiment and reveal information concerning productive jobs. Together these forces imply that in equilibrium the natural rate of unemployment is too high.

We would like to thank Boyan Jovanovic, Doug Staiger, and Joseph Tracy for helpful comments, and the National Science Foundation for financial support. 


\section{INTRODUCTION}

Following the seminal work of Friedman (1968) and Phelps (1968), much analysis of the natural rate of unemployment has focused on the relationship between allocative shocks and job search. Allocative shocks shift the demand for labor across products and locations and create an incentive for workers to move from one job to another. Frictional unemployment arises because it takes time and effort for the workers who relocate to find appropriate new jobs. There are by now many models concerning the connection between the allocative shocks, the search process, and the level and efficiency of the natural rate of unemployment, including Lucas and Prescott (1974), Hall (1979), Diamond (1981), and Mortensen (1982).

A common feature of these classical models of search unemployment is that a laid off worker just takes another draw from the distribution of wages in the economy. We believe that this trivializes the adjustment problem that an unemployed worker faces. The question facing this worker is often not whether to accept a given wage offer, but where even to begin looking for employment. What sectors are hiring? In what jobs will the worker be productive? Where are these jobs located?

Given the uncertainty that surrounds their adjustment decision, workers have an incentive to use all of the information at their disposal. In addition to their own search experience, they are likely to find the experience of others informative, especially the experience of other unemployed workers with similar characteristics who face similar adjustment decisions. In this paper, we analyze the incentives that confront a group of searchers who simultaneously find themselves unemployed due to a mass layoff. We examine the how the possibility of learning from others affects search behavior and the equilibrium rate of unemployment.

Labor market research suggests that learning from the example of other workers may help the unemployed overcome many of the difficulties inherent in adjustment. Somewhere between one half and two thirds of all jobs are obtained through connections with friends and relatives, and one prominent explanation for the prevalence of such informal channels is informational: a worker and a firm can learn about the quality of their match from the matches of others. ${ }^{1}$ Rees (1966)

1 See Montgomery (1991) for a brief overview of this literature. 
writes:

Employee referrals-the most important informal channel-usually provide good screening for employers who are satisfied with their present workforce. Present employees tend to refer people like themselves... The informal sources also have important benefits to the applicant. He can obtain much more information from a friend who does the kind of work in which he is interested than from an ad in the paper or a counselor at an employment agency.

Wanous (1992), in a study of recruitment methods, adds that:

Newcomers from an inside source are a better "match" to the organization because they had the opportunity to drop out from further consideration.... [Recruits from outside sources] will have substantial amounts of misinformation.

Finally, in a recent empirical study, Staiger (1990) concludes that his "evidence suggests that a personal contact may provide information that helps an individual find a good match."

There are times, however, when unemployed workers are likely to possess few useful connections and hence little information about their matches with firms. For example, if the shock that lead to the workers' unemployment was common to the sector or the region in which they were employed, then it is very likely that the workers will need to find new employment in unfamiliar locations or unfamiliar fields, and that many of the channels through which they normally would have obtained jobs will have been destroyed.

At such times there is another feature of labor markets that interacts with the fact that workers can learn from the experience of others: a large proportion of job losses result from mass layoffs. Davis and Haltiwanger (1992) report that plant closings account for $25 \%$ of job destruction, whereas plants in which the workforce contracts by less than $20 \%$ account for less than $25 \%$ of job destruction. The fact that workers are laid off in groups means that an unemployed worker has a natural peer group of fellow unemployed workers with similar skills and characteristics. Given that the members of this group face a major adjustment problem and are similar in many ways, there is the possibility that they may learn from one another's search. Has any other member of the group found a job? Where and in what sector? Have they succeeded at the job or is it a bad match? 
As these questions indicate, the process of the group gradually rebuilding its stock of information is riddled with informational spillovers. We focus on the way in which these informational spillovers affect worker reallocation and the natural rate of unemployment.

In this paper we develop a simple model of the natural rate of unemployment in which interactions among searchers are central. The basic microeconomic mechanism that we describe is one in which a group of workers are laid off and begin to search for new jobs. They learn about their suitability for different types of employment not only through their own search but also by watching the success or failure on the job of other workers with similar characteristics. It is the ability to learn from others that differentiates our model from previous models of search unemployment.

We show that this learning channel produces a natural rate of unemployment that is suboptimally high. The source of the inefficiency is the presence of an information externality and a free rider problem. Searchers have no incentive to take into account the value to others of the information revealed by their own search activity, but rather have an incentive to sit back and wait for others to reveal information through their search. Both of these effects lead searchers to be too selective in equilibrium. By waiting for others to reveal information, searchers fail to accept jobs that would provide valuable information to others.

While our emphasis on information externalities is new, we are not the first to develop models in which the natural rate of unemployment is inefficient. Tobin (1972) argued that congestion externalities would lead to a suboptimally high natural rate, a perspective that has recently been applied to Eastern European unemployment by Gavin (1992). Mortensen (1982) argued that meetings between workers and firms are a situation of bilateral monopoly; workers who reject matches fail to take into consideration the firm's rents and hence reject matches too often, implying again that the natural rate is too high. Diamond (1982) and Howitt (1988), on the other hand, show that thick market externalities may imply that the natural rate of unemployment is too low. Search is efficient in the model of Lucas and Prescott (1974).

Our approach also complements the existing literature on connections and employment. Formal models of this mechanism analyze why workers would choose to use connections to find employment [Holzer (1988)] or why workers with connections might earn higher wages than those who lack connections [Montgomery 
(1991), Mortensen and Vishwanath (1992), and Staiger (1990)]. To these we add the possibility that shocks to a sector or a region might leave unemployed workers with few connections to employed workers, and that group interactions may lead to suboptimal search in the presence of connections among unemployed workers.

In formal terms, the model that we develop is most closely related to our model of information spillovers and search in real estate markets [Caplin and Leahy (1993a)]. Other related models of information spillovers include the work of Banerjee (1992), Bikhchandani, Hirshleifer, and Welch (1992), Caplin and Leahy (1993b, 1993c, 1993d), and Rob (1991). Caplin and Leahy (1993b) and Atkeson and Kehoe (1992) present models in which sectoral reallocation destroys informational capital and reduces output; these models differ from the model contained in this paper in that Caplin and Leahy do not model search, and Atkeson and Kehoe do not model group learning.

The layout of the paper is as follows. Section 2 motivates our model of search with information spillovers and lays out the main assumptions. The solution to the model is presented in Section 3. Section 4 contains many of the main results including a discussion of the information externality and the free rider problem, a proof of the existence and uniqueness of equilibrium, and a demonstration that the natural rate is inefficient. Section 5 discusses various extensions to the model. Section 6 concludes.

\section{A MODEL OF SEARCH WITH INFORMATION SPILLOVERS}

We consider an economy with a continuum of different worker types indexed by $i \in[0,1]$ and a continuum of distinct industries indexed by $j \in[0,1]$. There are $N$ workers of each type $i$ and a continuum of firms of each type $j$. Each firm has a single job opening.

As in Jovanovic (1979), the fundamental allocative problem for the economy is to match workers to firms in which they are productive. We assume that there are two components to a worker's productivity, an idiosyncratic component $\phi$ that is specific to the match between a particular worker and firm, and a common component $\lambda_{i j}$ that influences the productivity of all workers of type $i$ in industry $j$. The driving force in the model is $\lambda_{i j}$. Fluctuations in this parameter will necessitate labor reallocation, and the fact that the parameter is common across workers of type $i$ will form the basis for learning during the adjustment process. 
We assume that $\lambda_{i j}$ follows a Markov process taking either the value zero which makes a worker completely unproductive in the industry or one which corresponds to high productivity. The transition probabilities between these two states are as follows: given that $\lambda_{i j}$ is equal to one in period $t$, the probability that it is equal to zero in period $t+1$ is $s$, and given that $\lambda_{i j}$ is equal to zero in period $t$, the probability that it is equal to one in period $t+1$ is equal to $v$. We assume that these transitions are independent across industry and worker types.

The assumptions on $\lambda_{i j}$ have two implications. First, because transitions are independent across worker types, type $i$ workers can learn nothing about their productivity in an industry from observing the productivity of workers of other types. Second, when $\lambda_{i j}$ becomes zero, all type $i$ workers in industry $j$ become unproductive and simultaneously begin to search elsewhere. This last property corresponds to the notion of mass layoffs in which many similar workers simultaneously find themselves unemployed.

We now describe the process of search when the entire group of $N$ type $i$ workers simultaneously find themselves unemployed. We assume that workers are risk neutral and that they choose their search strategies to maximize the expected present value of wages using discount rate $\beta$. Wages are assumed equal to the marginal productivity of workers, $\phi \lambda_{i j}$. Initially the only information that workers possess is their prior information concerning the distribution of job offers across the economy. The distribution of $\lambda_{i j}$ is determined by the Markov process. We assume that each idiosyncratic component $\phi$ is an independent draw from a uniform distribution on $[0,1]$.

In the first period of unemployment, each worker visits a single firm with a vacant job and receives an imperfect signal of their productivity on that job. The worker then must decide whether to accept or reject the job based on this signal and on the worker's prior beliefs. If they reject, they remain unemployed and receive nothing. If they accept they pay a cost $c$ and receive their marginal product $\phi \lambda_{i j}$. They remain in the job so long as $\lambda_{i j}$ equals one. The cost and irreversibility of job acceptance mean that accepting a job is an expensive and risky option. This will provide an incentive for workers to wait for others to reveal information about an industry through their search.

In the second period of unemployment, each worker who rejected a job gets to pick a new firm to search in. The key assumption is that they also have an opportunity to learn from the success or failure of others' search in the first period, 
and to use this information to guide their search activity. In order for observation of others' job acceptance to be valuable, it must be that it improves understanding of the common factor $\lambda_{i j}$. In general this would be a complicated signal extraction problem. We make two assumptions that simplify learning without altering the basic incentives affecting search. First, once one worker of type $i$ accepts a job, not only does this worker observe the common factor but so do all workers of type $i$. Second, the private signal that workers receive upon approaching a firm is simply the idiosyncratic component of productivity $\phi$, so that workers learn nothing about $\lambda_{i j}$ prior to acceptance.

This learning mechanism implies that if no other worker accepted a job in the first period, then the group learns nothing and will continue their blind process of search in the second period. If, on the other hand, anyone accepted a job in the first period, all workers learn their productivity in that industry. If workers of type $i$ learn that they are productive in industry $j$, they will have an incentive to search there, whereas if they learn that they are unproductive they will have an incentive to search somewhere else. In all subsequent periods search proceeds as in the second. In general, workers' search policies depend on whether or not the workers know that the industry in which they are searching is productive.

Note that the model as constructed is agnostic as to exactly how information passes among workers. One possible scenario is that workers observe the wage paid to employed individuals, and if this wage is positive they infer that the common factor is one. Another possibility is that workers observe whether the individual stays on the job or returns to the pool of searchers and infer from this the value of $\lambda_{i j}$. Finally, workers might learn that an industry is a good one directly by communicating with employed workers of their type.

We place one additional restriction on the search process: we assume that all workers of type $i$ search for employment in the same industry $j$. This simplifies the aggregation, because it prevents the group of $N$ type $i$ workers from splitting because two or more find employment in separate industries. It also ensures that all type $i$ workers are laid off simultaneously when $\lambda_{i j}$ becomes zero. Relaxing this assumption complicates the analysis, but gives rise to interesting phenomenon concerning an individual worker's decision whether or not to experiment by searching in other industries. We discuss the implications of relaxing this assumption in Section 5 . 
At the economy-wide level, the picture that emerges is one of many groups of workers searching for employment in a variety of markets. Members of each group sample firms in the same market. If one of them chooses to take a job, then all learn their productivity in that market. If this productivity is high they will choose to search further in this market. If it is low they will choose to search elsewhere. At the same time that the unemployed are searching for employment, the employed are losing their productive jobs at a rate $s$.

In this setting we look for a steady state Nash equilibrium in search strategies. The model is structured so that workers are in one of three states. They are either employed or, if unemployed, they either know of a good industry or are completely uninformed. Employed workers make no strategic decisions. They remain on the job until they become unproductive. A strategy for an unemployed worker consists of rules describing which jobs to accept in each of the two states of unemployment. The structure of the model is simple enough that in the next section we show that both rules are of the reservation variety. Therefore the Nash equilibrium has two parameters $\bar{\phi}$ and $\hat{\phi}$ that describe the reservation acceptance levels. Once we have solved for $\bar{\phi}$ and $\hat{\phi}$, we can use the steady state distribution of workers between employment and the two unemployed states to complete the characterization of equilibrium and the natural rate.

DEFINITION: An equilibrium consists of search cutoff rules $\bar{\phi}$ for the uninformed searcher and $\hat{\phi}$ for the informed searcher such that it is optimal for each uninformed worker to accept jobs if and only if $\phi>\bar{\phi}$ and each informed worker to accept jobs if and only if $\phi>\hat{\phi}$ provided others are pursuing this strategy.

We need to place one restriction on the parameters in order for the model to be interesting. For any search to take place, we need that the ex ante present discounted value of a job with the highest idiosyncratic match component be greater than the cost of accepting employment. As we shall see below the expected value of wages earned on a job for which $\phi$ is equal to one is $\left(\frac{v}{s+v}\right)\left(\frac{1}{1-\beta(1-s)}\right)$. We need this to be greater than $c$.

Overall the data of model are $N, s, v, c$, and $\beta$. The first measures the size of layoffs; the second and third concern the amount of sectoral reallocation; the fourth is the cost of experimentation; and the last is the discount rate. In the next sections we show that given these data there is a unique equilibrium and describe how changes in the parameters effect the equilibrium rate of unemployment. 


\section{THE SOLUTION TO THE MODEL}

We begin by analyzing the optimal search policy of a collection of $N$ workers of the same type. We then imbed this search strategy into an aggregate framework.

\section{A. Optimal Search}

The search behavior of workers will depend on whether or not previous search has revealed markets with high $\lambda_{i j}$. We must therefore consider searching workers in two states: an uninformed state in which the worker must search for a productive market, and an informed state in which the worker limits search to markets which are known to have $\lambda_{i j}$ equal to one.

Let $V(\phi)$ denote the value the optimal search strategy for an uninformed worker who currently possesses an idiosyncratic match component $\phi$. The worker has two choices: accept the job or ignore the current offer and wait for the next period. $V(\phi)$ is simply the maximum of these two choices,

$$
V(\phi)=\max \{A, W\},
$$

where $A$ is the expected value of accepting the job and $W$ is the expected value of waiting.

The value of accepting is:

$$
A=\alpha p \phi+\alpha p s \beta V^{e}+(1-p) \beta V^{e}-c
$$

where $\alpha=1 /(1-\beta(1-s)), p=v /(s+v)$, and $V^{e}$ denotes the unconditional expectation of $V(\phi)$. To understand this equation note that if a worker accepts a job, the worker pays $c$ and observes the common component $\lambda_{i j}$. The probability that the common component is high is equal to the steady state proportion of industries with $\lambda_{i j}$ equal to one. Given the transition probabilities $s$ and $v$, it follows that this probability is equal to $p$. If the common component is high then the worker receives the wage $\phi$ so long as the job survives. Good matches expire with probability $s$ so that the present value of wages is $\alpha \phi$. When a match expires all workers of type $i$ become unemployed and uninformed. Hence when a match expires the worker receives the expected value of being in the uninformed state. If a worker discovers that the common component is low upon accepting a job, then again the worker remains uninformed and receives $V^{e}$.

The value of waiting, $W$, will depend on the actions of others. If one worker of type $i$ discovers a job of type $j$ in which $\lambda_{i j}$ is one, then all workers of type $i$ will 
benefit from the information. If, on the other hand, no agent of type $i$ finds a good match, all agents of type $i$ will remain uninformed. ${ }^{2}$ Let $\pi$ denote the probability that a worker becomes informed through others' search. The value of waiting is then,

$$
W=\beta\left[\pi J^{e}+(1-\pi) V^{e}\right]
$$

where $J^{e}$ is the expected value of an optimal search strategy in the informed state.

Since the value of waiting is independent of the particular realization of $\phi$, whereas the value of accepting is strictly increasing in $\phi$, the optimal policy is to set a reservation level of $\phi$ and to accept a job whenever $\phi$ exceeds this level. The reservation level $\bar{\phi}$ equates the value of accepting and waiting. A little algebra yields

$$
\alpha p \bar{\phi}-c=\beta \pi J^{e}+[(1-\pi)-(1-p)-\alpha p s] \beta V^{e}
$$

We can now use $\bar{\phi}$ to calculate the expected value of an optimal search policy in the uninformed state. If the draw of $\phi$.is above $\bar{\phi}$ the worker accepts the job, otherwise the worker waits. Hence

$$
V^{e}=\int V(\phi) d \phi=\int_{0}^{\bar{\phi}} W d \phi+\int_{\bar{\phi}}^{1}\left[\alpha p \phi+\alpha p s \beta V^{e}+(1-p) \beta V^{e}-c\right] d \phi
$$

Eliminating $W$ and solving for $V^{e}$,

$$
V^{e}=\frac{\pi J^{e}+\frac{1}{2} \alpha p\left(1-\bar{\phi}^{2}\right)-(1-\bar{\phi}) c}{1-(1-\bar{\phi})(\alpha p s+1-p) \beta-\bar{\phi}(1-\pi) \beta}
$$

We can also use $\bar{\phi}$ to calculate the probability that a worker who waits will become informed through others search,

$$
\pi=p(1-s)\left(1-\bar{\phi}^{N-1}\right)
$$

Here we have used the fact that in a symmetric Nash equilibrium each agent is following strategy $\bar{\phi}$ so that the probability that at least one other agent accepts a job is $1-\bar{\phi}^{N-1}$. This job is productive with probability $p$ and survives with probability $1-s$.

2 Note that it makes no difference whether all workers reject jobs or a single worker accepts and discovers that the industry is bad. In either case all the workers end up in the uninformed state. 
The search decision in the informed state is quite similar. The worker chooses between accepting a job and further search,

$$
J(\phi)=\max \left\{\alpha \phi+\alpha s \beta V^{e}-c, \beta(1-s) J^{e}+s V^{e}\right\} .
$$

Here the fact that the worker is informed implies that the probability that the match is productive is equal to one, and the value of waiting depends on the probability that the match will expire. Again the optimal strategy is to accept only matches that exceed some minimal threshold $\hat{\phi}$ at which the worker is indifferent between accepting and waiting,

$$
\alpha \hat{\phi}+\alpha s \beta V^{e}-c=(1-s) \beta J^{e}+s \beta V^{e} .
$$

Finally, with $\hat{\phi}$, we can calculate $J^{e}$ :

$$
\begin{aligned}
J^{e} & =\int_{0}^{\hat{\phi}}\left(\alpha \hat{\phi}+\alpha s \beta V^{e}-c\right) d \phi+\int_{\hat{\phi}}^{1}\left(\alpha \phi+\alpha s \beta V^{e}-c\right) d \phi \\
& =\frac{\alpha}{2}\left(1+\hat{\phi}^{2}\right)+\alpha s \beta V^{e}-c .
\end{aligned}
$$

Equations (3.1) through ( 3.4) form a system of four equations in the four unknowns $\bar{\phi}, \hat{\phi}, V^{e}$, and $J^{e}$. The solution to these equations defines the equilibrium search strategies. We now imbed this search behavior into the aggregate framework.

\section{B. Aggregation}

The steady-state unemployment rate is determined from four parameters: the separation rate $s$, the steady state probability that a match is productive $p$, and two reservation match parameters $\bar{\phi}$ and $\hat{\phi}$. As usual the way to solve for the natural rate is to equate flows between states. Figure 1 illustrate the flows between employment and the two states of unemployment. Let $E$ denote the fraction of the labor force that is currently employed, and let $I$ and $U$ denote the fractions of the labor force that are informed and uninformed respectively.

The first relation between $E, I$ and $U$ is the adding up constraint. As proportions they must sum to one,

$$
E+I+U=1 .
$$

The second relation between $E, I$ and $U$ comes from equating flows into and out of the uninformed state,

$$
s(E+I)=p(1-s)\left(1-\bar{\phi}^{N}\right) U .
$$




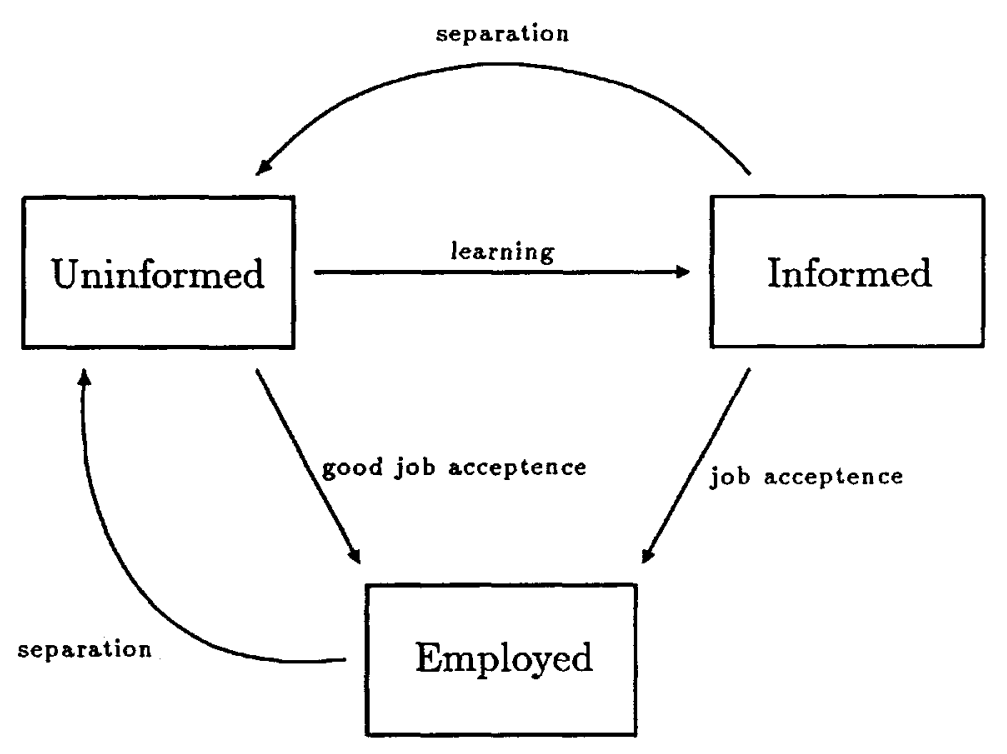

\section{Figure 1}

Flows into the uninformed state are the result of separations. Since each period a fraction $s$ of all matches between industries and types become unproductive, these flows are $s(E+I)$. The right hand side of equation (3.6) is the flow out of the uninformed state. If any one of a group of $N$ workers of a given type $i$ finds a good match, then the entire group leaves the uninformed state. The probability of this occurring is $p\left(1-\bar{\phi}^{N}\right)$ and $(1-s)$ is the probability that this match survives one period.

Finally, equating the flows into and out of employment gives us a third relationship between $E, I$, and $U$,

$$
(1-s)(1-\hat{\phi}) I+p(1-s)(1-\bar{\phi}) U=s E .
$$

The right side of equation (3.7) gives the exit rate from employment. The left side of the equation gives the entry rate which is equal to the probability of accepting a match from each of the two unemployment states multiplied by the probability that the match is high and the survival rate for productive matches.

We can solve equations (3.5)-(3.7) for the employment rate

$$
E=\frac{p(1-s)\left[1-\bar{\phi}-\hat{\phi}(1-s)\left(1-\bar{\phi}^{N}\right)\right]}{(s+(1-s)(1-\hat{\phi}))(s+p(1-s)(1-\bar{\phi}))} .
$$


This completes the solution to the model.

\section{ANALYSIS}

\section{A. The Free Rider Problem and the Information Externality}

Several features of the model are immediately apparent from the equations. According to equation (3.1), all else equal $\bar{\phi}$ is increasing in $\pi$, the probability that the worker becomes informed through others search. The possibility that search by others will reveal information concerning the location of productive markets therefore increases the value of waiting and causes the uninformed worker to be more selective. Each agent therefore has an incentive to delay matching in order to free ride off the information revealed by others. In many models, most notably Grossman and Stiglitz (1980), the incentive to free ride leads to non-existence of equilibrium. In contrast, in Section $4 \mathrm{~B}$ we show that there always exists an equilibrium to this model and that this equilibrium is unique.

Another feature of the model may be seen from the definition of $\pi$ : increases in $\bar{\phi}$ reduce $\pi$. Therefore if one worker of type $i$ becomes more selective, the probability that all other workers of type $i$ will become informed falls. Since an individual searcher ignores this effect in choosing the cutoff $\bar{\phi}$, there is an informational externality in the model; agents ignore the value to others of the information revealed through their matches. The presence of this externality will cause Nash equilibrium to be inefficient. We return to welfare issues and analyze the social planner's problem in Section $4 \mathrm{C}$ below.

While we speak of the free rider problem and the information externality as separate forces, they are really reflections of the same phenomenon. If there were no information externality, that is if the action of one agent did not affect to payoffs of others, then there would be no incentive to free ride. Similarly, if agents could not wait to take advantage of the information revealed by others, then the fact that actions reveal information would be of no importance.

\section{B. Existence and Uniqueness}

Proposition 1 demonstrates both the existence and uniqueness of equilibrium.

Proposition 1: There exists a unique solution to equations (3.1)-(3.4) with $\bar{\phi}, \hat{\phi} \in(0,1)$. 


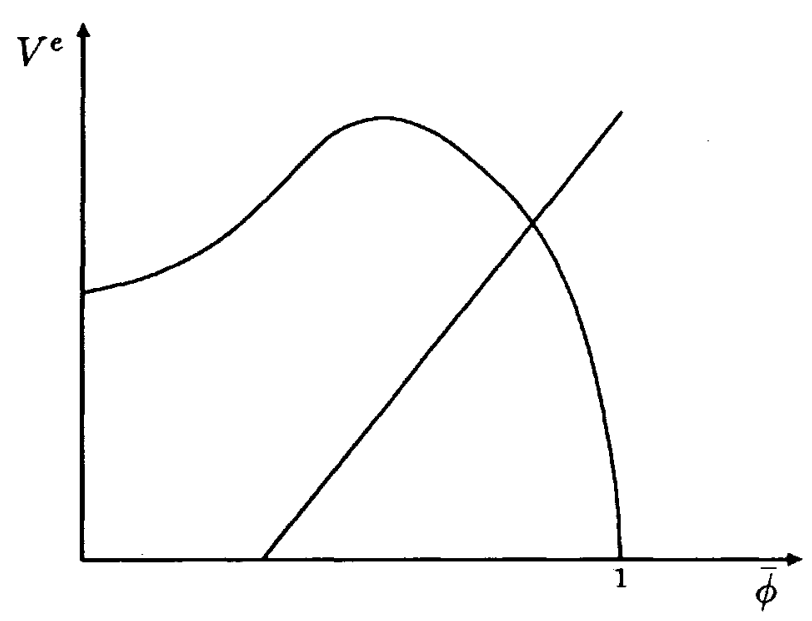

Figure 2

Proof: See Appendix.

The proof of the proposition is contained in the appendix. The main argument is presented in Figure 2. First we show that $V^{e}$ in equation (3.2) is a quasiconcave function of $\bar{\phi}$ and that $V^{e}$ is equal to zero when $\bar{\phi}$ is equal to one. Next we show that $V^{e}$ in equation (3.1) is an increasing function of $\bar{\phi}$ and that $\bar{\phi} \in(0,1)$ when $V^{e}$ is equal to zero. Finally, we show that the $V^{e}$ that solve equation (3.1) for a given $\bar{\phi}$ lie below the $V^{e}$ that satisfy a social planners first order condition, so that the intersection between (3.1) and (3.2) is unique and occurs to the right of the maximum in (3.2). ${ }^{3}$

\section{The Socially Optimal Search Strategy}

In Nash equilibrium each agent chooses an optimal strategy given the strategies chosen by others. In contrast, the social planner chooses all agent's strategies simultaneously so as to maximize their collective utility. In the present situation in which all agents are identical the planner's problem takes the form of maximizing the utility of any one agent subject to the constraint that all agents follow symmetric strategies.

3 The reason that equilibrium exists in spite of the presence of the free rider problem is that reservation wage strategies are natural mixed strategies, where the mixing is done through the draw of the idiosyncratic parameter $\phi$. This contrasts with the pure strategies that underlie the famous non-existence result of Grossman and Stiglitz. 
The equations that characterize the social planner's problem are not that different from those that characterize the Nash equilibrium. Equations (3.3) and (3.4) continue to hold, as the determination of the cutoff in the informed state conditional on $V^{e}$ is efficient. The change is that the social planner chooses a cutoff in the uninformed state $\phi^{*}$ to maximize $V^{e}$ in equation (3.2) taking into account that $\pi$ is a function of $\phi^{*}$.

Proposition 2 states that $\phi^{*}<\bar{\phi}$. This can be seen from Figure 2 that shows that the intersection that determines $\bar{\phi}$ lies to the right of the maximum value of $V^{e}$.

Proposition 2: A social planner who maximizes the collective utility of workers would choose a cutoff in the uninformed state that is lower than the Nash equilibrium cutoff, $\phi^{*}<\bar{\phi}$.

Proof: See Appendix.

The gap between $\phi^{*}$ and $\bar{\phi}$ is the result of the information externality and the free rider problem. These cause searchers to be too cautious. Searchers pass up matches that may bring valuable information and they wait for information to be delivered by the actions of others.

Note that the social planner will also choose a lower value for $\hat{\phi}$. This is not due to any externality in the informed state, but rather to the fact that job separations link valuations in the two states. For this reason increases in $V^{e}$ tend to reduce $\hat{\phi}$ as can be seen from equation (3.3).

Algebraic manipulation shows that $\partial E / \partial \bar{\phi}$ and $\partial E / \partial \hat{\phi}$ are negative. Therefore the fact that both $\bar{\phi}$ and $\hat{\phi}$ are inefficiently high in Nash equilibrium implies that the natural rate of unemployment is inefficiently high as well.

The type of policies that the model suggests are policies that lead both informed and uninformed workers to accept employment more readily. These might include subsidizing the hiring of workers and improving the formal channels through which information is conveyed to unemployed workers. Other policies such as unemployment insurance may exacerbate the information problem because they reduce the incentive to accept jobs.

\section{The Comparative Statics of $N$}

Possibly the most interesting comparative static parameter in the model is the size of a cohort $N$. Differentiating equation (3.1), (3.2) with respect to $N$ 
and solving for $d \bar{\phi} / d N$ we see that increases in $N$ raise the cutoff for acceptance in the uninformed state

$$
\frac{d \bar{\phi}}{d N}=\beta \frac{\left(J^{e}-V^{e}\right) \frac{\partial \pi}{\partial N}}{\alpha p \frac{1-\beta(1-\pi)-\beta \pi \frac{d J^{e}}{d V e}}{1-\alpha p s \beta-(1-p) \beta}-\beta\left(J^{e}-V^{e}\right) \frac{\partial \pi}{\partial \bar{\phi}}} \geq 0 .
$$

The inequality follows from the fact that $\partial \pi / \partial \bar{\phi}<0, \partial \pi / \partial N>0$, and $J^{e}>V^{\mathrm{e}}{ }^{4}$ The intuition underlying this result is that increases in $N$ increase the probability that someone else will investigate the market. This in turn increases the value of waiting and the incentive to free ride. Hence $\bar{\phi}$ rises and each worker becomes more selective. It is easy to see from equation (3.2) that $V^{e}$ rises with $\bar{\phi}$ so that workers are also better off the larger their cohort.

How does the social planners cutoff $\phi^{*}$ vary with $N$ ? There are two effects. First, as $N$ rises, the value of finding a good match increases as there are more workers who will benefit from becoming informed. This effect implies that $\phi^{*}$ should fall as $N$ rises. Second, as $N$ rises duplication of search costs becomes an issue. The social planner wants to avoid too many searchers incurring the cost $c$ when the industry is unproductive. This effect implies that $\phi^{*}$ should rise as $N$ rises. Simulations of the model indicate that the derivative of $\phi^{*}$ with respect to $N$ is ambiguous due to these two conflicting effects.

Another variable that has an ambiguous derivative with respect to $N$ is the duration of unemployment. Let $D_{U}$ denote the expected duration in the uninformed state, and $D_{I}$ the expected duration in the informed state, then

$$
D_{U}=(1-p(1-\bar{\phi}))\left[1+\pi D_{I}+(1-\pi) D_{U}\right] .
$$

The expected duration of unemployment in the uninformed state is simply the probability that the agent remains unemployed in the current period plus the expected duration given that the agent remains unemployed. The latter depends on whether or not the agent becomes informed. Solving for $D_{U}$,

$$
D_{U}=\frac{(1-p(1-\bar{\phi}))\left(1+\pi D_{I}\right)}{1-(1-p(1-\bar{\phi}))(1-\pi)}
$$

The direct effect of an increase in $N$ is to increase $\pi$ and to reduce $D_{U}$; an increase in $\pi$ reduces the duration of unemployment by increasing the probability

$4 J^{e}$ is greater than $V^{e}$ because better information makes agents better off. A formal proof of this fact is contained in Lemma 1 in the appendix. 
that the worker will enter the informed state where jobs come more quickly. An increase in $N$ however has two other effects that work in the other direction. An increase in $N$ increases $\bar{\phi}$ which reduces the probability of finding a job on one's own. An increase in $N$ also increases $V^{\mathrm{e}}$ which increases $\hat{\phi}$ and therefore increases the duration of unemployment in the informed state. This indicates that the derivative of $D_{U}$ with respect to $N$ is ambiguous. Simulations of the model showed that this was in fact the case.

Generally the longer are spells, the higher will be the natural rate of unemployment. So it is not surprising that just as in duration analysis, the derivative of $E$ with respect to $N$ is ambiguous. Given $\bar{\phi}$, an increase in $N$ increases the probability that workers will become informed, and since the probability of becoming employed from the informed state is greater than from the uninformed state, this has the effect of increasing the employment rate. The increase in $N$, however, also leads to increases in $\bar{\phi}$ and $\hat{\phi}$ that reduce the flow out of unemployment.

\section{E. Limit Behavior}

As $N$ rises to infinity, one of two situations may occur. If $\lim _{N \rightarrow \infty} \bar{\phi}<1$, then $\bar{\phi}^{N-1}$ approaches zero and $\pi$ approaches $p(1-s)$. It is very possible, however, that with $\pi=p(1-s)$ the incentive to free ride is so strong that it is optimal for a worker to set $\bar{\phi}$ equal to one. If this is the case, then as $N$ approaches infinity, workers become so selective that $\bar{\phi}$ approaches one and $\bar{\phi}^{N-1}$ approaches some limit between zero and one. Thus even as the number of searchers becomes very large, it is not necessarily the case that information about productivity gets out quickly. As $N$ rises there are more workers searching, but each becomes more selective.

\section{DISCUSSION AND EXTENSIONS}

In this section we discuss several issues raised by the model, as well as how the model might be extended in the light of these issues. We organize the discussion around a series of questions: What is the nature of the group interaction among searchers? When is group search likely to be important? What happens if searchers may recall prior offers? What are the incentives to experiment by searching in other industries? We take up these questions in turn.

\section{A. The Nature of the Interaction among Searchers}


As it is modelled, the information externality and the free rider problem affect the cutoff for accepting a job. It is clear that there are many other margins upon which these forces might operate. For example, the results would have been similar if the crucial decision that a searcher had to make was how much effort to expend in finding a job. In deciding how hard to search, a worker might not take account of the benefits search provides others. The worker would also have an incentive to relax and allow others to expend effort on search. Similarly the margin might involve the decision to move to a new location or to develop new skills. Each of these decisions involve potential information spillovers, and therefore the potential for insufficient search.

There is one potential interaction that appears to introduce an incentive for excessive search. Suppose that there were only $M$ jobs in each industry, and that $M$ is less than the number of workers of type $N$. The fact that there are fewer jobs than searchers appears to create an incentive to be the first one to accept a job in an industry, since then one is assured of a productive job, whereas followers may be left out. ${ }^{5}$ This argument, however, ignores the fact that unless the number of productive industries is also limited, the ability to search elsewhere places a floor on the value of being unemployed. The fact that someone else accepts a job appears more likely to help via the information channel than to hurt by making jobs scarce. The fact that someone else accepts a job cannot be harmful, unless the total number of jobs for a specific type of worker is limited.

\section{B. When is Group Search Important?}

Group search is likely to be important when two conditions are met. First, it is necessary that there be a group of unemployed workers with similar characteristics who can learn from one another's search. As discussed in the introduction this is likely to be the case when there are mass layoffs. Workers from the same firm are likely to share many of the same skills, as well as social and economic characteristics. The second condition is that workers lack perfect channels of information concerning the location of productive jobs, so that they value the information that they might obtain from others' search.

It is clear that shocks will differ in how well they meet these conditions. For example, large, permanent shocks are more likely to lead to plant closings

5 In general, this sort of behavior need not lead to a lower unemployment rate. See Jovanovic (1987). 
and mass layoffs, whereas shocks to a sector or region are more likely to destroy information channels. Idiosyncratic shocks to a firm, on the other hand, may destroy less information. Workers who are laid off from a struggling firm in a thriving industry or region may have friends in other firms in the industry or region through which they can obtain jobs. In such cases, learning from other unemployed workers may prove to be less important.

We can easily amend the model to include both industry and firm specific shocks. We only have to note that separation need not necessarily send a worker into the uninformed state. If the separation is due to a firm shock the worker enters the informed state instead. The worker loses a job, but not the knowledge that the industry is productive.

Suppose that industry shocks occur with probability $s_{i}$ and firm shocks occur with probability $s_{f}$. Then defining $\tilde{\alpha}=1 /\left(1-\beta\left(1-s_{i}-s_{f}\right)\right.$, equations (3.1) and (3.3) are amended as follows

$\left(3.1^{\prime}\right) \tilde{\alpha} p \bar{\phi}+\tilde{\alpha} s_{i} p \beta V^{e}+\tilde{\alpha} s_{f} p \beta J^{e}+(1-p) \beta V^{e}-c=\pi \beta J^{e}-(1-\pi) \beta V^{e}$

$$
\tilde{\alpha} \hat{\phi}+\tilde{\alpha} s_{i} \beta V^{e}+\tilde{\alpha} s_{f} \beta J^{e}+(1-p) \beta V^{e}-c=\left(1-s_{i}\right) \beta J^{e}-s_{i} \beta V^{e} .
$$

Equations (3.2) and (3.4) are unaffected. $\pi$ is equal to $p\left(1-s_{i}\right)\left(1-\bar{\phi}^{N}\right)$.

It is straight forward to show that if we hold $s_{i}+s_{f}$ fixed, increases in $s_{i}$ raise both $\bar{\phi}$ and $\hat{\phi}$, and hence the natural rate of unemployment. It is therefore possible that fluctuations in the natural rate could arise from fluctuations in the relative importance of industry and firm specific shocks.

The clean separation between shocks to industries and shocks to firms is somewhat misleading. It makes it appear that if workers retain any connections to other employed workers then they do not need to learn from others' search and that they only learn from others search if all connections to employed workers are destroyed. This is really a consequence of our simplifying assumptions on the learning process. In general, workers face a complex signal extraction problem. Some of the information that they receive prior to employment reflects factors common to all workers and some of the information that they receive subsequent to employment is idiosyncratic. In addition, the characteristics that workers share with other workers are not one dimensional; workers share some characteristics with some workers and other characteristics with other workers. All of this means that there is really a continuum of shocks, each of which leads to situations in which group search is more or less important. Each shock places a group of workers out 
of work. Their ability to learn from each other will depend on how similar they are. Some of these workers may be well connected to workers in other industries and may find new jobs quite easily. Others workers will lack connections and will therefore find the information revealed through group search of some value.

\section{Search with Recall}

One feature of the model is that we do not allow workers to recall past job offers. In many search models this is an innocuous assumption, since offers that were rejected in the past will be rejected again in the present. In the current setting, however, the possibility that uninformed workers may become informed means that allowing recall may make a difference.

There are two possibilities depending on whether or not $\bar{\phi}>\hat{\phi}$ in the equilibrium without recall. If $\bar{\phi}<\hat{\phi}$, then allowing recall makes no difference, since recalled offers will always fall below the reservation acceptance level. The logic is the standard one: the reservation match equates the value of accepting any current offer and waiting, it does not matter how many current offers there are.

If, however, $\hat{\phi}<\bar{\phi}$ then some offers that would be rejected in the uninformed state would be acceptable in the informed state. If we allow recall, these offers may be accepted as soon as it is discovered that the market is good. The possession of these offers therefore increases the value of becoming informed and hence the value of waiting in the uninformed state. Allowing recall in these cases will tend to increase the incentive to free ride and raise $\bar{\phi}$. Recall therefore raises the natural rate of unemployment.

\section{Experimentation}

Possibly the most severe restriction placed upon the model was the requirement that all workers of a given type search in the same market. We now discuss the implications of relaxing this assumption.

The first thing to note is that workers have an incentive to search in separate industries. Consider a worker who accepts a job in an industry in which the common match parameter is low. If that worker is searching in the same industry as all other workers then there is no way that the worker can benefit from the search behavior of others; the worker knows that because they are in the same industry any jobs that they accept will also have low productivity. If, however, the worker 
is searching elsewhere, then it is possible that the worker will become informed even though the industry in which the worker is searching is unproductive.

The immediate implication of the fact that workers search in different industries is that it makes aggregation difficult. It multiplies the number of possible states in which a group of $N$ workers might find themselves. It is possible that several workers may find jobs in separate industries at the same time, and workers' welfare will depend on how many different industries are known to have good matches at any given time. Workers who know of only one good industry become uninformed upon separation, whereas workers who know of several may search in one of the surviving industries.

In spite of this apparent complexity, there are several qualitative points concerning the nature of this equilibrium that may be addressed verbally. ${ }^{6}$ First, even if all workers search in separate industries in the uninformed state, there is still too little experimentation in the informed state. Once a worker learns of a good industry, the worker has no incentive to continue searching elsewhere. There is, however, a social benefit to discovering other productive industries so that workers who lose their jobs know where to search in order to find productive ones. A social planner may want to dedicate a small subset of workers of a given type to the task of searching for new markets in which the common match component is high.

A second qualitative feature of such an equilibrium is that even though uninformed workers have an incentive to search in separate industries, it is still the case that the private incentive to diversify is not as strong as the social incentive. To see this suppose that industries differed in their ex ante probability of having a good match. This amendment creates an incentive to search in the best industry that counteracts the incentive to search away from the crowd. There exists some differential in the probabilities between the most promising industry and the next most promising industry such that if all workers were searching in the most promising industry, each worker would be indifferent between continuing to search there and searching elsewhere. In this case there is no private incentive to diversify search, but there is still a social incentive. Whereas a worker that chooses to search in another market neither gains nor loses, all other workers gain. If the most promising market turns out to be unproductive, these workers will

\footnotetext{
6 See Caplin and Leahy (1993e) for a more formal treatment of the issues raised in this discussion.
} 
need to look elsewhere for employment and will benefit from knowing the locations of other productive industries. Therefore once again there may be too little experimentation in equilibrium.

\section{CONCLUSION}

We have constructed a model of job search in which unemployed workers learn from the experience of other unemployed workers. We have shown that this interaction among searchers leads both to an information externality and an incentive to free ride, and that these imply that the natural rate of unemployment is suboptimally high. The model suggests that policies designed to encourage experimentation and improve the information possessed by the unemployed may improve welfare. 


\section{APPENDIX}

We need one preliminary result in order to prove Propositions 1 and 2.

Lemma 1: $J^{e}>V^{e}$.

Proof: (sketch) Let $\Omega$ be the set of bounded, continuous functions $F$ : $[0,1] \rightarrow[0,1 /(1-\beta)]$ with the sup norm. The following defines a mapping from $\Omega \times \Omega \rightarrow \Omega \times \Omega$ :

$$
\begin{aligned}
V_{n}(\phi) & =\max \left\{\alpha p \phi+(\alpha p s \beta+1-p) V_{n+1}^{e}-c, \phi \beta J_{n-1}^{e}-(1-\pi) \beta V_{n-1}^{e}\right\} \\
J(\phi) & =\max \left\{\alpha \phi+(\alpha s \beta+1-p) V_{n-1}^{e}-c,(1-s) J_{n-1}^{e}-s \beta V_{n-1}^{e}\right\}
\end{aligned}
$$

Here $\pi$ is exogenous and held at its equilibrium level.

Let $J_{0}=V_{0}=0$. It follows that $J_{1}>V_{1}$. It also follows that $J_{n-1}>V_{n-1}$ implies $J_{n}>V_{n}$. This follows from the fact that $\pi<1-s$ and when jobs are accepted $\alpha \phi+\alpha s \beta V^{e}>\beta V^{e}$.

Standard dynamic programming arguments show that the mapping described above is a contraction. It therefore has a unique fixed point to which all initial values converge. Hence our sequence converges to $J^{e}$ and $V^{e}$ and since $J_{n}>V_{n}$ for all $n$, it must be the case that $J^{e}>V^{e}$ as well. This completes the proof. Q.E.D.

One proof establishes Propositions 1 and 2.

Proposition 1: There exists a unique solution to equations (3.1)-(3.4) with $\bar{\phi}, \hat{\phi} \in(0,1)$.

Proposition 2: A social planner who maximizes the collective utility of workers would choose a cutoff in the uninformed state that is lower than the Nash equilibrium cutoff.

Proof: (sketch) Existence hinges on the presence of a $\bar{\phi}$ that lies between $[0,1]$ and satisfies equations (3.1) through (3.4). The determination of $\hat{\phi}$ is standard.

Consider equation (3.2). It gives the value of being uninformed given that everyone follows the same policy $\tilde{\phi}$ (we use $\tilde{\phi}$ to denote an arbitrary policy and reserve $\bar{\phi}$ for the Nash equilibrium):

$$
V^{e}=\frac{\tilde{\phi} \pi \beta J^{e}+\frac{\alpha p}{2}\left(1-\tilde{\phi}^{2}\right)+(1-\tilde{\phi}) c}{1-(1-\tilde{\phi})(\alpha p s \beta+(1-p) \beta)-\tilde{\phi}(1-\pi) \beta} .
$$


Note that when $\tilde{\phi}$ equals one $V^{e}$ equals zero.

We now show that equation (7.1) describes $V^{e}$ as a quasiconcave function of $\tilde{\phi}$. Differentiating with respect to $\tilde{\phi}$

$$
\frac{d V^{e}}{d \tilde{\phi}}=\frac{\pi \beta J^{e}-\alpha p \bar{\phi}+c+\tilde{\phi} \beta\left(J^{e}-V^{e}\right) \frac{d \pi}{d \tilde{\phi}}}{1-\left(1-\tilde{\phi}(1-p+\alpha s \beta p)-\tilde{\phi}(1-\pi) \beta-\phi \pi \beta \frac{d J^{e}}{d V^{e}}\right.} .
$$

Note that this derivative is positive when $\tilde{\phi}$ equals one. $d V^{e} / d \tilde{\phi}$ gives the first order condition for a social planner,

(7.2) $\left.\alpha p \tilde{\phi}-c+[1-p+\alpha p s] \beta V^{e}=p(1-s)\left(1-N \tilde{\phi}^{N-1}\right) J^{e}\right)+p(1-s) N \tilde{\phi}^{N-1} V^{e}$.

The set of $V^{e}$ and $\tilde{\phi}$ that satisfy this first order condition have two useful properties. First, when $V^{e}$ is zero, $\tilde{\phi} \in(0,1)$. Second, as $\tilde{\phi}$ increases, $V^{e}$ increases. Together these properties imply that $V^{e}$ has a single maximum. This is because when $V^{e}$ from equation (7.1) satisfies equation (7.2) it must have a zero derivative, but since the locus of solutions to equation (7.2) is increasing this is only possible at one point. Hence $V^{e}$ is quasiconcave.

The Nash equilibrium $V^{e}$ and $\bar{\phi}$ must satisfy both equation (7.1) and the first order condition (3.1)

$$
\alpha p \tilde{\phi}-c=\pi \beta J^{e}+\left[(1-\pi \beta-(1-p) \beta-\alpha p s \beta] V^{e} .\right.
$$

The important property of this equation is that given $\tilde{\phi}$ the $V^{e}$ that solves (3.1) lies below the $V^{e}$ that satisfies the social planners first order condition. This implies that (3.1) intersects (7.1) at a point in which $\bar{\phi}$ is greater than the social maximum and $V^{e}$ is less than the social maximum. This completes the proof. Q.E.D. 


\section{REFERENCES}

Atkeson, Andrew, and Patrick Kehoe (1992): "Industry Evolution and Transition: The Role of Informational Capital, " mimeo, Univ. of Chicago.

BAnerJee, AbHiJit (1992): "A Simple Model of Herd Behavior," Quarterly Journal of Economics 107, 797-818.

Bikhchandani, Sushil, David Hirschleifer, and Ivo Welch (1992): "A Theory of Fads, Fashion, Custom, and Cultural Change as Informational Cascades," Journal of Political Economy 100, 992-1026.

Caplin, Andrew, And John Leahy (1993a): "Miracle on Sixth Avenue: Information Externalities and Search, " mimeo, Columbia Univ..

Caplin, AndRew, AND John Leahy (1993b): "Sectoral Shocks, Learning, and Aggregate Fluctuations," Review of Economic Studies 60, 777-794.

Caplin, ANDREW, AND John LEAHy (1993c): "Business as Usual, Market Crashes, and Wisdom after the Fact," American Economic Review, forthcoming..

Caplin, Andrew, and John Leahy (1993d): "The Economics of Adjustment," in Rod Cross, ed., The Natural Rate of Unemployment Twenty Years On, Cambridge: Cambridge University Press, forthcoming.

Caplin, Andrew, and John Leahy (1993e): "Imitation," mimeo, Columbia Univ..

Davis, Steven, and John Haltiwanger (1992): "Gross Job Creation, Gross Job Destruction, and Employment," Quarterly Journal of Economics 107, 819-864.

Diamond, Peter (1981): "Mobility Costs, Frictional Unemployment, and Efficiency," Journal of Political Economy 89, 798-812.

Friedman, Milton (1968): "The Role of Monetary Policy," American Economic Review 56, $1-17$.

Grossman, Sanford, and Joseph Stiglitz (1980): "On the Impossibility of Informationally Efficient Markets," American Economic Review 70, 393-408.

HALL, RoberT (1979): "A Theory of the Natural Unemployment Rate and the Duration of Employment," Journal of Monetary Economics 5, 159-169.

Holzer, HARRY (1988): "Seach Method Use by Unemployed Youth," Journal of Labor Economics 6, 1-20.

HowitT, Peter (1988): "Business Cycles with Costly Search and Recruiting," Quarterly Journal of Economics 103, 147-166.

Jovanovic, Boyan (1979): "Job Matching and the Theory of Turnover," Journal of Political Economy 87, 972-990.

Jovanovic, Boyan (1987): "Work, Rest, and Search: Unemployment, Turnover, and the Cycle," Journal of Labor Economics 5, 131-148.

Lucas, Robert, and Edward Prescott (1974): "Equilibrium Search and Unemployment," Journal of Economic Theory 7, 188-209.

Montgomery, James (1991): "Social Networks and Labor-Market Outcomes: Toward an Economic Analysis," American Economic Review 81, 1408-1418.

Mortensen, Dale (1982): "The Matching Process as a Non-Cooperative Bargaining Game, " in J. McCall, ed., The Economics of Information and Uncertainty, Chicago: University of Chicago Press.

Mortensen, Dale, and Tara Vishwanath (1992): "Personal Contacts and Earnings: It is Who You Know!, "Labour Economics, forthcoming.

Phelps, Edmund (1968): "Money-Wage Dynamics and Labor-Market Equilibrium," Journal of Political Economy 76, .

ReEs, Albert (1966): "Information Networks in Labor Markets," American Economic Review 56, 559-566. 
RoB, Rafael (July 1991): "Learning and Capacity Expansion under Demand Uncertainty," Review of Economic Studies 58, 655-675.

STAIGER, Doug (1990): "The Effect of Connections on the Wages and Mobility of Young Workers, " mimeo, M.I.T..

Tobin, James (1972): "Inflation and Unemployment," American Economic Review 60, $1-18$.

Wanous, John (1992): Organizational Entry. Reading, MA: Addison-Wesley. 


\author{
1993-94 Discussion Paper Series \\ Department of Economics \\ Columbia University \\ 420 W. 118 St., Room 1022 \\ New York, N.Y., 10027 \\ Librarian: Angie $\mathrm{Ng}$
}

The following papers are published in the 1993-94 Columbia University Discussion Paper series which runs from November 1 to October 31. Domestic orders for discussion papers are available for purchase at $\$ 5.00$ (U.S.) each and $\$ 140.00$ (U.S.) for the series. Foreign orders cost $\$ 8.00$ (U.S.) for individual paper and $\$ 185.00$ for the series. To order discussion papers, please send your check or money order payable to Department of Economics, Columbia University to the above address. Please be sure to include the series number for the paper when you place an order.

671. Investment in U.S. Education and Training

Jacob Mincer ( Nov. 1993)

672. Freer Trade and the Wages of the Unskilled: Is Marx Striking Again?

Jagdish Bhagwati and Vivek Dehejia

673. Employer Size and Labor Turnover

Todd Idson

674. Less Crime May Be Worse

Brendan O'Flaherty

675. Team Production Effects on Earnings

Todd Idson

676. Language, Employment. and Earnings in the United States:

Spanish-English Differentials from 1970 to 1990

David Bloom and Gilles Grenier

677. The Impact of Performance Incentives on Providing Job Training

to the Poor: The Job Training to the Poor: The Job Training Partnership

Act (JTPA)

Michael Cragg

678. The Demands to Reduce Domestic Diversity among Trading Nations Jagdish Bhagwati

679. Mass Layotfs and L'nemployment

Andrew Caplin and John Leahy 
680. The Economics of Adjustment

Andrew Caplin and John Leahy

681. Miracie on Sixth Avenue: Information Externalities and Search

Andrew Caplin and John Leahy

682. Irbitrage. Gains trom Trade and Scoial Diversity: A Unified Perspective on Resource Allocation

Graciela Chichilnisky

683. Who should abate carbon emissions?

Graciela Chichilnisky, Geoffrey Heal

684. Believing in Multiple Equilibria

(iraciela Chichilnisky

485. imited Arbitrage. Gains trom rade and Arrow's Theorem (iracıela Chichilnisky

686. Internatıonal Emission Permits: Equity and Efficiency

(jraciela Chichilnisky. (jeolfrey Heal and David Starrett 